\title{
REPAIR OF THE TRUNCAL VALVE AND ASSOCIATED INTERRUPTED ARCH IN NEONATES WITH TRUNCUS ARTERIOSUS
}

Marjan Jahangiri, FRCS David Zurakowski, PhD John E. Mayer, MD

Pedro J. del Nido, MD

Richard A. Jonas, MD
Objective: Truncal valve regurgitation and interrupted aortic arch have frequently been identified as risk factors in the repair of truncus arteriosus. We wished to examine these factors in the current era including the impact of truncal valve repair. Methods: Between January 1992 and August 1998, 50 patients underwent surgical repair of truncus arteriosus. Their ages ranged from 2 days to 6 months (median, 2 weeks). Nine patients had associated interrupted aortic arch. Of the 14 patients $(28 \%)$ in whom truncal valve regurgitation was diagnosed preoperatively, 5 had mild regurgitation, 5 had moderate regurgitation, and 4 had severe regurgitation. Five underwent truncal valve repair and 1 underwent homograft replacement of the truncal valve with coronary reimplantation. Results: The actuarial survival was $96 \%$ at 30 days, 1 year, and 3 years. There were no deaths in patients with associated interrupted aortic arch. The 2 deaths in the series occurred in patients with truncal valve regurgitation, neither of whom underwent repair. Postoperative transthoracic echocardiography in patients who underwent valve repair showed minimal residual valvular regurgitation. None of the patients has required reoperation because of truncal valve problems or aortic arch stenosis at a median follow-up of 23 months (range, 1-60 months). Conduit replacement has been done in 17 patients (34\%) after a mean duration of 2 years. The freedom from reoperation for those who had an aortic homograft was 4 years and for those who had a pulmonary homograft was 3 years. Conclusion: Despite the magnitude of the operation, excellent results can be achieved in complex forms of truncus arteriosus. In the current era interrupted aortic arch is no longer a risk factor for repair of truncus. Aggressive application of truncal valvuloplasty methods should neutralize the traditional risk factor of truncal valve regurgitation. (J Thorac Cardiovasc Surg 2000;119:508-14) $r$ uncus arteriosus is a rare congenital heart malformation that results from failure of septation of the embryonic truncus arteriosus and failure of normal septation of the conus. A single arterial trunk leaves the heart through a single semilunar valve and supplies the

From the Department of Cardiac Surgery, Children's Hospital, Boston, Mass.

Read at the Seventy-ninth Annual Meeting of The American Association for Thoracic Surgery, New Orleans, La, April 18-21, 1999.

Received for publication April 22, 1999; revisions requested July 19, 1999; revisions received Nov 2, 1999; accepted for publication Nov 2, 1999.

Address for reprints: Richard A. Jonas, MD, Department of Cardiac Surgery, Children's Hospital, 300 Longwood Ave, Boston, MA 02115 .

Copyright $@ 2000$ by Mosby, Inc.

$0022-5223 / 2000 \$ 12.00+0 \quad \mathbf{1 2 / 6 / 1 0 4 1 5 1}$

doi:10.1067/mtc.2000.104151 aorta, one or both pulmonary arteries, and the coronary arteries. The anulus of the truncal valve is larger than a normal semilunar valve and is placed in the normal aortic position. In the majority of cases, the semilunar valve has 2 to 4 cusps, and in rare instances valves with 5 cusps have been reported (tricuspid, 70\%; tetracuspid, $23 \%$; bicuspid, $6 \%$; pentacuspid, $2 \%) .{ }^{1}$ In addition to the abnormal number of cusps, there may be commissural imperfection and nodularity causing prolapse. ${ }^{2}$

Primary repair of truncus arteriosus during the neonatal period and infancy has become the established practice. ${ }^{3,4}$ The excellent results of surgical repair of truncus arteriosus reported in most centers have not applied to those patients with significant truncal valve regurgitation and associated interrupted arch. Truncal valve dysfunction is estimated to occur in up to $25 \%$ of patients with truncus arteriosus. ${ }^{5}$ This figure may be an under- 
estimation of truncal valve dysfunction because of the large runoff of blood to the pulmonary circulation. In some series, valve regurgitation was identified by poor hemodynamic performance when the patient was weaned from cardiopulmonary bypass (CPB). The surgical options for truncal valve regurgitation have been homograft replacement with coronary reimplantation, mechanical valve replacement, and valve repair. The first two options condemn the patient to multiple further operations with risks of eventual valve failure, anticoagulation, and prosthetic valve endocarditis. The recently reported disappointing results of homograft valve replacement ${ }^{6,7}$ make truncal valve repair a more attractive option. In an earlier series from Children's Hospital, Boston, truncal valve regurgitation and interrupted aortic arch were identified as risk factors for perioperative death. ${ }^{3}$

The purpose of this study was to examine the treatment of patients with truncal valve regurgitation and interrupted aortic arch in the current era and to compare the outcome in these cases with that in the less complex forms of truncus arteriosus.

\section{Patients and methods}

In the previous published series of truncus arteriosus from Children's Hospital, Boston, the cases of patients who had undergone repair between September 1986 and December 1991 were reviewed. ${ }^{3}$ The current series encompasses January 1992 to September 1998. The hospital records of all patients who underwent repair of truncus arteriosus between January 1992 and August 1998 were reviewed. There were no patients with the diagnosis of truncus arteriosus who died before operation. Fifty patients were identified: 31 boys and 19 girls. The ages ranged from 2 days to 6 months (median, 2 weeks). Weights ranged from $1.6 \mathrm{~kg}$ to $6.1 \mathrm{~kg}$ (median, 3.1 $\mathrm{kg}$ ). Three patients were born prematurely, 2 at 31 weeks' gestation and 1 at 30 weeks' gestation, weighing at birth 1.6, 1.6 , and $1.4 \mathrm{~kg}$, respectively. All patients underwent primary repair. Diagnosis was made in all patients by transthoracic echocardiography alone. Repair was achieved in 37 patients (74\%) in the first month of life. The delayed repair in the remainder was because of late referral. Associated cardiac anomalies are shown in Table I.

Surgical technique. The repair was done with the use of deep hypothermia with continuous $\mathrm{CPB}$ or reduced flow usually with a single venous cannula. A period of circulatory arrest was used in 15 patients (30\%). The CPB, crossclamp, and circulatory arrest times are shown in Table II. The truncus was usually divided at the level of takeoff of the pulmonary arteries and great care was taken to ensure that an adequate margin from the coronary arteries was maintained. The truncal root was anastomosed to the ascending aorta. This necessitated considerable tailoring of the large truncal root, which may have improved valve leaflet apposition. The
Table I. Morphologic characteristics

\begin{tabular}{|c|c|}
\hline Characteristic & $N$ \\
\hline TVR & 14 \\
\hline Mild & 5 \\
\hline Moderate & 5 \\
\hline Severe & 4 \\
\hline IAA & 9 \\
\hline Type A & 1 \\
\hline Type B & 8 \\
\hline Coronary anomalies & 5 \\
\hline
\end{tabular}

TVR, Truncal valve regurgitation; IAA, interrupted aortic arch.

ventricular septal defect was approached through the right ventriculotomy and was closed with interrupted pledget-supported sutures using glutaraldehyde-treated autologous pericardium or Dacron fabric. The right ventricular outflow tract was reconstructed with either an aortic or pulmonary homograft. The patent foramen ovale was left open, and if this was not patent a small atrial communication was made.

Patients with truncal valve regurgitation. Fourteen patients $(28 \%)$ with truncal valve regurgitation were identified preoperatively. Of the 14 patients, 5 had mild regurgitation, 5 had moderate regurgitation, and 4 had severe regurgitation. Five patients with moderate to severe regurgitation underwent valve repair and 1 patient underwent homograft root replacement. Three patients with moderate truncal valve regurgitation did not undergo repair. These patients were from the earlier part of the series when truncal valve problems were not specifically addressed.

The principle of valve repair was improved leaflet apposition. This was achieved by approximation of the incomplete commissures and resuspension of the true commissures. The rudimentary commissures were closed with 7-0 Prolene polypropylene sutures supported with pericardial pledgets. If there was some redundancy in the anulus, this was reduced by taking a tuck at the attachment of the raphe of the commissure and the aortic wall. Reduction of the sinuses of Valsalva was done when indicated. Three patients had quadricusp valves, in which 2 cusps were relatively normal and the other 2 cusps were partially fused at a rudimentary commissure. One patient had 5 leaflets with 3 large leaflets and 2 additional leaflets. The fifth patient had a bicuspid valve. A 5-dayold neonate weighing $2.9 \mathrm{~kg}$ with severe truncal valve regurgitation underwent homograft root replacement (aortic homograft, $11 \mathrm{~mm}$ ) with coronary reimplantation. This patient was operated on early in the series.

Patients with interrupted aortic arch. Associated interrupted aortic arch was repaired in 9 patients. Eight patients had type B and 1 patient had type A interrupted arch. The median age was 17 days (range, 4 days -6 months). Seven patients were younger than 1 month old, 1 was 6 weeks old, and another was 6 months old. None of the patients with associated interrupted aortic arch had truncal valve regurgitation.

After wide mobilization of the ascending and descending aorta and control of the arch vessels, direct anastomosis was 
Table II. CPB, crossclamp, and circulatory arrest times

\begin{tabular}{lcccccc}
\hline Group & $n$ & CPB (min) & $n$ & Crossclamp (min) & $n$ & Arrest (min) \\
\hline All patients & 50 & $128(79-209)$ & 50 & $68(26-116)$ & 15 & $33(6-76)$ \\
TVR & 14 & $110(79-184)$ & 14 & $67(26-96)$ & 2 & $18(6-30)$ \\
No TVR & 36 & $130(84-209)$ & 36 & $70(44-116)$ & 4 & $34(19-76)$ \\
IAA & 9 & $157(131-209)$ & 9 & $87(72-116)$ & 9 & $40(22-76)$ \\
No IAA & 41 & $121(79-184)^{*}$ & 41 & $66(26-102)^{*}$ & - \\
\hline
\end{tabular}

Values represent median time in minutes with ranges given in parentheses. Data from patients with and without truncal valve regurgitation (TVR) and interrupted aortic arch $(I A A)$ were compared for each of these variables.

$* P<.001$, Mann-Whitney $U$ test; all other comparisons were not significant.

achieved in 5 patients. In the other 4 patients partial direct anastomosis was augmented with a pericardial or homograft gusset.

Statistical analysis. Median age, weight, and time to reoperation were compared by the Mann-Whitney $U$ test. Differences in CPB, crossclamp, and circulatory arrest times were evaluated by the unpaired Student $t$ test. The analysis of reoperation was done with the Cox proportional hazard model, ${ }^{8}$ using the following variables: age, weight at operation, sex, presence of truncal valve regurgitation, interrupted aortic arch, CPB time, and crossclamp time. Percent survival at 30 days, 1 year, and 3 years and freedom from reoperation were determined by the Kaplan-Meier product-limit method and a $95 \%$ confidence interval estimated by the Greenwood formula. ${ }^{9}$ Two-tailed values of probability $(P)$ were determined. Data analysis was done with the SPSS software package (version 8.0, SPSS Inc, Chicago, Ill).

\section{Results}

There were 2 perioperative deaths (4\%) in 50 patients who underwent repair of truncus arteriosus and associated lesions. One death occurred in the first year of this series. This was in a 5-day-old boy weighing $2.9 \mathrm{~kg}$ who had severe truncal valve regurgitation. He underwent homograft root replacement with reimplantation of the coronary arteries. CPB was ceased with administration of large doses of inotropic agents. The chest was left open. In the early postoperative period, respiratory failure and abdominal distension developed. An attempt at insertion of a peritoneal dialysis catheter resulted in liver hemorrhage. The patient died on postoperative day 4.

The second death was in a 2-week-old boy weighing $3.5 \mathrm{~kg}$. This patient had mild to moderate truncal valve regurgitation and dual origin of the left anterior descending coronary artery. After repair, the patient was weaned from CPB with moderate support. He had complete heart block and pacing was required. One hour after arrival in the intensive care unit he had a cardiac arrest and after resuscitation was placed on extracorporeal membrane oxygenation (ECMO) support.
There was no suggestion of tamponade or pulmonary hypertensive crisis accounting for the arrest. The next 48 hours were complicated by severe coagulopathy and bleeding. Transesophageal echocardiography revealed poor left ventricular function and a thrombosed conduit. The patient was returned to the operating room for replacement of the conduit and subsequently was maintained on ECMO support for a further 48 hours. His course was complicated by Aspergillus mediastinitis. It was also demonstrated that the excised homograft was infected with Aspergillus. All attempts at weaning from ECMO were unsuccessful and at this point the patient had overwhelming sepsis. Resuscitation was ceased.

Patients with truncal valve regurgitation. There were 2 deaths in the group of patients with truncal valve regurgitation. Both cases were discussed in the preceding section. Of the 5 patients who underwent truncal valve repair, none died. Two patients had transesophageal echocardiography done in the operating room after weaning from CPB that showed minimal valvular regurgitation. Transthoracic echocardiography done after the operation in all patients having repair showed mild valvular regurgitation in 2 patients and 3 patients had no truncal valve regurgitation.

Transthoracic echocardiography at the most recent follow-up showed minimal valvular regurgitation in the 5 patients who underwent repair. Of the 8 patients who did not undergo truncal valve repair or replacement, 5 with mild truncal valve regurgitation and 2 with moderate truncal valve regurgitation did not have any deterioration of valve function at follow-up. One patient with moderate valvular regurgitation has had some deterioration in valve function.

Patients with associated interrupted aortic arch. There were no deaths in the group of patients with associated interrupted aortic arch, and the median hospital stay was not significantly different from the stay in those patients without interrupted aortic arch. Obstruction across the arch anastomosis was defined as a pressure gradient of $30 \mathrm{~mm} \mathrm{Hg}$ or greater defined by 


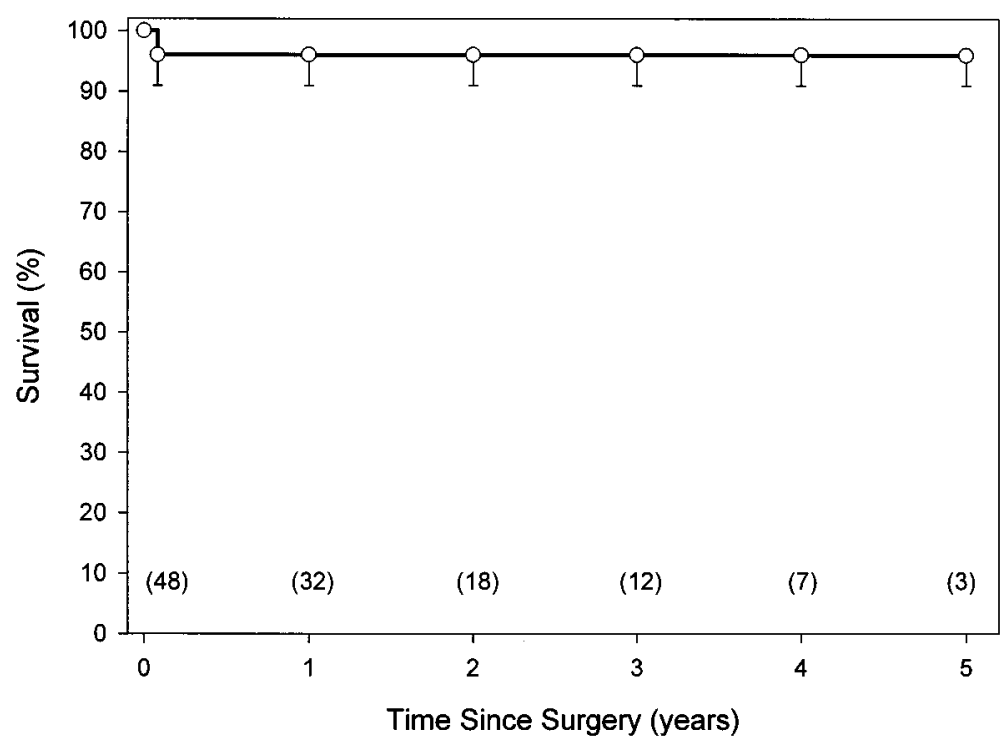

Fig 1. Kaplan-Meier time-related survival.

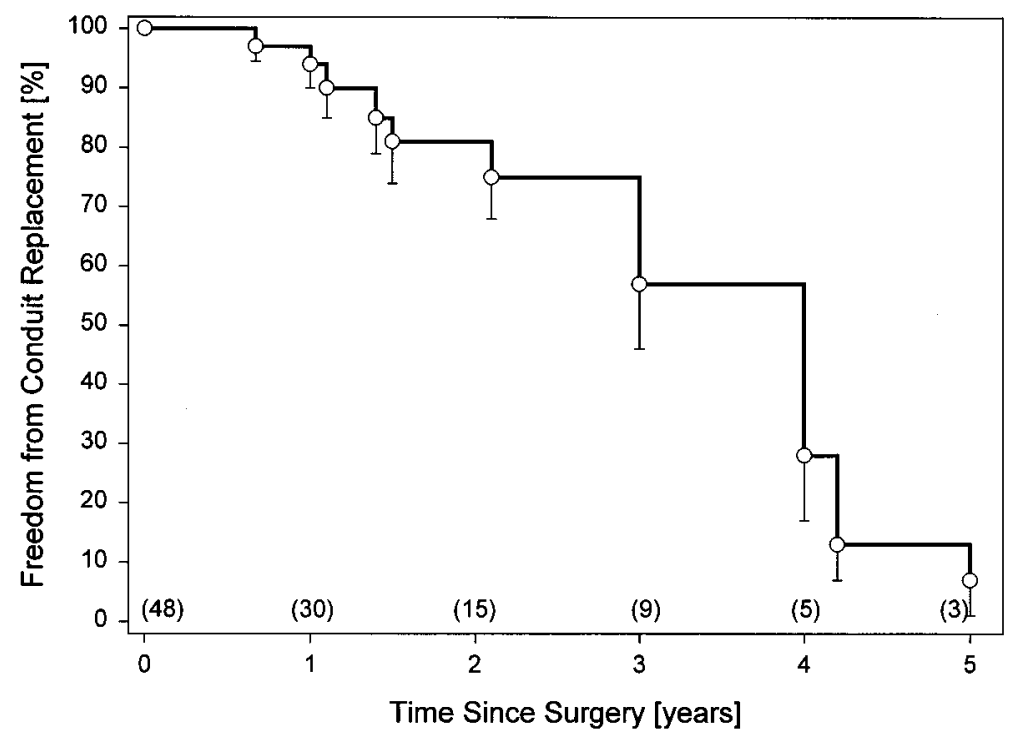

Fig 2. Kaplan-Meier time-related freedom from conduit replacement. The numbers of remaining patients at risk are shown in parentheses at the appropriate points. Error bars represent the lower $95 \%$ confidence limits.

transthoracic echocardiography. At follow-up, none of the patients had any degree of arch obstruction.

Freedom from reoperation. Conduit replacement has been done in 17 patients (34\%) with a median interval of 3 years. The median aortic homograft size at the initial operation was $10 \mathrm{~mm}$ and the median pulmonary homograft size was also $10 \mathrm{~mm}$. The median time for reoperation for patients who had an aortic homograft was 4 years (range, 8 months -7 years) and for those who had a pulmonary homograft, 3 years (range, 11 months -4 years). This difference was not significant ( $P$ $=.87)$. By the Cox proportional hazard model, patients with a larger homograft size had a longer period of freedom from conduit replacement. None of the patients has required reoperation because of truncal valve problems or aortic arch stenosis. The actuarial survival was $96 \%$ at 30 days, 1 year, and 3 years (Fig 1). Freedom from reoperation is shown in Fig 2. 
Follow-up. The follow-up was complete in all 48 patients (median, 23 months; range, 1-60 months). The mean follow-up for patients with interrupted aortic arch was 13 months (range, 1-48 months) and for patients with truncal valve regurgitation, 14 months (range, 3-36 months).

\section{Discussion}

In this study, the more complex forms of truncus arteriosus, those with truncal valve regurgitation and associated interrupted aortic arch, are analyzed. These associated anomalies were previously identified as risk factors for death after repair of truncus arteriosus. ${ }^{3}$

The disappointing results of truncal valve replacement and the success of aortic valve repair in the adult population have increased interest in the repair of truncal valve insufficiency. ${ }^{10-12}$ In this study, 5 patients underwent truncal valve repair. In all 5 patients, truncal valve insufficiency was diagnosed preoperatively and therefore valve repair was a planned procedure. In the most recent previous series from Children's Hospital, Boston, 4 of 8 patients with truncal valve insufficiency died. On further analysis of the 4 deaths, only 1 patient had replacement as a planned part of the primary repair. In another, valve replacement was done after failure to wean from CPB. Two patients died in the perioperative period before valve replacement could be accomplished. Of the 4 patients who survived, 2 underwent perioperative valve replacement and 2 underwent replacement at 6 and 12 months, respectively. In the current series, none of the patients who underwent truncal valve repair has required intervention at a median follow-up of 14 months (range, 3-36 months).

It is thought that nodular or dysmorphic valves are more likely to be insufficient and have an abnormal number of leaflets ${ }^{2}$ and that quadricusp valves are more regurgitant than tricuspid valves. ${ }^{13}$ In this study, the number of patients who underwent truncal valve repair is too small to extrapolate as to which type of valve would best be served by valvuloplasty techniques. Most probably, conversion of a quadricusp valve to a tricuspid valve will be most productive, because it will restore a trileaflet morphology. It may be that repair resulting in bicuspid morphology would predispose to future valve stenosis.

The results of truncal valve replacement have been disappointing. In the current series, the 1 patient who underwent truncal valve replacement because of valve regurgitation died in the postoperative period. Elkins and colleagues ${ }^{7}$ have reported the cases of 4 patients who underwent homograft replacement of the truncal valve, 2 of whom died in the early postoperative peri- od. In a report by McElhinney and colleagues, ${ }^{14} 3$ of the 4 neonates who received allograft root replacement died within 7 months after repair and the fourth required replacement after 1 year because of severe homograft insufficiency. Four of their 6 patients who required mechanical valve replacement died in the early postoperative period. The risks of mechanical valve replacement in the small truncal root, impairing normal growth of the native anulus as well as subjecting the child to long-term anticoagulation, should be weighed against potential benefits.

The results in this series with associated interrupted arch have improved significantly compared with results in the previous report, ${ }^{3}$ in which 3 of 6 patients died after repair. There were no deaths in the 9 patients who underwent complete repair. Of the 9 patients who underwent repair, 7 were younger than 1 month old.

We advocate direct anastomosis between the ascending and the descending aorta. A gusset of homograft can be used for augmentation of the anastomosis if there is important size disparity. Others have suggested the use of subclavian artery in type A interrupted aortic arch and the use of both the subclavian and the left carotid arteries in type B interrupted aortic arch. ${ }^{15}$ In this method, the arch vessels are divided distally and then filleted open to form the superior part of the neo-aortic arch. Those authors believe that the risk of stenosis is reduced. However, this has to be balanced against the risk of cerebral damage. ${ }^{16}$ At a mean follow-up of 13 months (range, 1-48 months), none of the patients in our series has been seen because of restenosis. Although the follow-up is too short in this group to draw any inferences regarding the method of repair, it is unlikely that circumferential anastomosis per se will result in stenosis, as has been shown in infants and neonates who have undergone the arterial switch operation. ${ }^{17}$

In conclusion, despite the magnitude of this operation, excellent results can be achieved in complex forms of truncus arteriosus. We advocate complete onestage repair in these patients. In patients with truncal valve regurgitation, valve repair is a preferable option to valve replacement. In the current era, associated interrupted aortic arch may no longer be associated with increased mortality in patients undergoing repair of truncus arteriosus.

\section{REFERENCES}

1. Crupi GI, Macartney FJ, Anderson RH. Persistent truncus arteriosus. Pediatr Cardiol 1977;40:569-78.

2. Becker AE, Becker MJ, Edwards JE. Pathology of the semilunar valve in persistent ductus arteriosus. J Thorac Cardiovasc Surg 1971;62:16-26.

3. Hanley FL, Heinemann MK, Jonas RA, Mayer JM, Cook NR, 
Wessel DL, et al. Repair of truncus arteriosus in the neonate. J Thorac Cardiovasc Surg 1993;105:1047-56.

4. Bove EL, Lupinetti MF, Pridjian AK, Beekman RH, Callow LB, Snider AR, et al. Results of a policy of primary repair of truncus arteriosus in the neonate. J Thorac Cardiovasc Surg 1993;105: 1057-66.

5. Freedom RM. Anomalies of aortopulmonary septation: persistent truncus arteriosus, aortopulmonary septal defect, and hemitruncus arteriosus. In: Freedom RM, Benson LN, Smallhorn JF, editors. Neonatal heart disease. London: Springer-Verlag; 1992. p. 428-52.

6. Elami A, Laks H, Pearl JM. Truncal valve repair: initial experience with infants and children. Ann Thorac Surg 1994;57:397402.

7. Elkins RC, Steinberg JB, Razook JD, Ward KE, Overholt ED, Thompson WM. Correction of truncus arteriosus with truncal valvar stenosis or insufficiency using two homografts. Ann Thorac Surg 1990;50:728-33.

8. Hosmer DW, Lemeshow S. Applied survival analysis: regression modeling of time to event data. New York: John Wiley; 1999. p. 93-105.

9. Cox DR, Oakes D. Analysis of survival data. London: Chapman and Hall; 1994. p. 48-56.

10. Duran CM. Present status of reconstructive surgery for aortic valve disease. J Card Surg 1993;8:443-52.

11. Cosgrove DM, Rosenkranz ER, Henzden WG, Barlett JC, Stewart WJ. Valvuloplasty for aortic insufficiency. J Thorac Cardiovasc Surg 1991;102:571-7.

12. Black MD, Adatia I, Freedom RM. Truncal valve repair: initial experience in neonates. Ann Thorac Surg 1998;65:1737-40.

13. Bharati S, Lev M. Truncus arteriosus communis. In: The pathology of congenital heart disease: a personal experience with more than 6300 congenitally malformed hearts. Armonk [NY]: Futura; 1996. p. 353-80.

14. McElhinney DB, Reddy MV, Rajasinghe HA, Mora BN, Silverman NH, Hanley FL. Trends in the management of truncal valve insufficiency. Ann Thorac Surg 1998;65:517-24.

15. Dietl CA, Torres AR. Repair of interrupted aortic arch with an augmented aortic anastomosis. Ann Thorac Surg 1993;56:142-8.

16. Jonas RA. Modified arch anastomosis for interrupted aortic arch. Ann Thorac Surg 1993;56:5-6.

17. Wernovsky G, Mayer JE, Jonas RA, Hanley FL, Blackstone EH, Kirklin JW, et al. Factors influencing early and late outcome of the arterial switch operation for transposition of the great arteries. J Thorac Cardiovasc Surg 1995;109:289-302.

\section{Discussion}

Dr Edward L. Bove (Ann Arbor, Mich). Dr Jonas and his associates from Boston have presented an outstanding series of repair of truncus arteriosus, demonstrating that excellent outcomes can be expected in the modern era for this condition, even with associated interrupted aortic arch and truncal valve regurgitation.

Not long ago many authors, including those from the current report, found that repair of truncus arteriosus was associated with a higher mortality when there was coexisting arch interruption or truncal valve regurgitation. Why are the results better now? Although the answers are not always readily apparent from a retrospective data review, it seems clear that a number of factors, including earlier age at operation, better preoperative and postoperative management, and increased experience with the repair of arch abnormalities of all kinds in neonates, have played significant roles.

Importantly, however, the results presented today also indicate that truncal valve repair is a particularly useful option in the management of significant truncal valve regurgitation. This knowledge will allow surgeons to avoid the delay in operation that has so often been used when the truncal valve must be dealt with and also to avoid the technical complexity introduced by truncal valve replacement itself, thus removing arguably the two most significant risk factors associated with the need for truncal valve replacement.

A few years ago, our group reported excellent survival with severe truncal valve regurgitation when truncal valve replacement was undertaken without delay, even in neonates, indicating that delaying the operation plays an important role in the outcome, as also demonstrated for uncomplicated truncus, and that operating on a patient with worsening left ventricular dysfunction and in poor preoperative condition was itself associated with a higher risk. Thus prompt truncal valve replacement can be done satisfactorily. However, the problems associated with the need for repeated replacement of the truncal valve in growing babies present yet another set of risks that can and should be avoided by early valve repair as demonstrated by the authors. However, although it appears that repair is possible even in severely malformed valves, the limitations of this technique are not fully understood.

Similarly outstanding results can now be expected with associated interruption of the arch, a condition that has not posed an increased risk in our institution for a considerable time. The authors prefer a primary anastomosis, a technique with which we would agree, although arch augmentation with a homograft patch is another useful tool that allows for a better size match between the distal aorta and the often small segment of ascending aorta that is left after removal of the duct and the pulmonary arteries. We have increasingly used the Lecompte maneuver to translocate the branch pulmonary arteries anteriorly to facilitate conduit placement.

I have three main questions for Dr Jonas. First, you used repair of the truncal valve in 5 of the 9 patients in your series who had at least moderate regurgitation. Although no doubt your indications were evolving over time, could you tell us why the other 4 patients were not treated in a similar fashion and what their postoperative outcomes and echocardiograms showed? Do you now recommend repair for any patient with at least moderate regurgitation?

Second, have you identified any morphologic characteristics of the truncal valve that may be predictive of successful repair? In particular, what about those valves that are very immobile, often with significant degrees of stenosis? It has certainly been our experience that patients with severe truncal valve regurgitation also have gradients across the valve, admittedly because of the large volume flow, but often also because of the very thickened and immobile leaflets.

Finally, have you seen any bronchial obstruction after your technique of repair of the interrupted aortic arch? 
Dr Jonas. The reason that all patients with at least moderate regurgitation did not have repair is that this has been a combined experience of several surgeons. I have been enthusiastic about truncal valve repair for some time, but I believe now all of us in Boston are catching on to this idea.

I think your second point is one of the important reasons we have started to become more enthusiastic, and that is because of an appreciation that gradients detected across these valves preoperatively are usually eliminated by eliminating the regurgitation. The same has been true with aortic valve repairs as well in that much of the supposed stenosis is in fact an artifact and simply a reflection of the huge volume load that these valves are carrying before operation. Remember that not only are truncal valves carrying the regurgitant fraction but they are also carrying the entire pulmonary blood flow. I personally have yet to see a valve that has had fixed immobile leaflets that would not be suitable for repair. Perhaps they do exist and perhaps one would not be able to repair them, but I think they are rare.

As to the status of the patients with moderate regurgitation who did not receive repair, I would like to call on Dr Jahangiri to comment. As far as I am aware, none has required a subsequent valve operation, so I believe that they have remained in stable condition. However, certainly our threshold for repairing valves is constantly coming down and that applies to both aortic valves and truncal valves.

Regarding bronchial obstruction, I think we learned a long time ago with simple interrupted aortic arch that very wide mobilization of the descending aorta and the arch vessels is important, and that one has to bring the head vessels down as well as bring the descending aorta up to the anastomosis. This helps reduce the tension on the anastomosis, which fundamentally is the cause of left bronchial obstruction.

I believe also the concept of dividing the truncus rather than taking the pulmonary arteries off the side is important.
Often a major bulge out of the left side of the truncus will result if you simply take the pulmonary arteries off. Especially if you have essentially type I truncus and simply take the pulmonary arteries off, leaving the ascending aorta in continuity, then the routing of the conduit becomes complex and can result in compression of the conduit, compression of the coronary arteries, and so on. I think by shifting the whole trunk rightward by doing a complete division, and also tailoring the rest down to improve the valve, one avoids obstructive problems all around.

Dr V. Mohan Reddy (San Francisco, Calif). Dr Jahangiri and Dr Jonas and their group have shown excellent results. I definitely agree with their conclusion. Our experience says that truncal valve repair is the preferred treatment in these patients. In our early experience, we tended to use allograft replacement. Certainly all the patients survived, but within a few months severe allograft regurgitation developed, and we subsequently gave up using allografts in favor of repair. I would like to ask Dr Jonas what happened to the one patient in whom you had replaced the truncal valve with an allograft?

Dr Jonas. Dr Jahangiri, can you clarify that for us? I do not recall reoperating on that patient, but certainly we have seen accelerated calcification when we have used homografts. Did that patient require reoperation?

Dr Jahangiri. That patient was one of those who died in the series. We had to leave the chest open because the heart was swollen with increasing edema. The patient was sent to the intensive care unit and required considerable inotropic support. Subsequently, in the next 48 hours, candidiasis developed and the patient died of uncontrolled sepsis.

Dr Reddy. I would like to add a cautionary note. When allografts were placed in neonates with associated very severe regurgitation, allograft regurgitation developed within 3 months. We did this procedure in 4 patients early in our experience and all of them required replacement within the first 6 months. 